\title{
LA PREGUNTA POR LA DIFERENCIA DE REGÍMENES EN EL PENSAMIENTO ARENDTIANO
}

\author{
MATÍAS SIRCZUK \\ Universitat Pompeu Fabra
}

\begin{abstract}
¿Es posible pensar, tras la ruina de la tradición de la filosofía política, la diferencia entre diversas formas de organización política? En este artículo propongo abordar este interrogante en dos partes. En la primera parte, me centraré en mostrar cómo, en su lectura de Montesquieu, Arendt descubre un modo de pensar la oposición entre libertad y dominación que trasciende los horizontes clásicos. En la segunda parte, analizaré las dos experiencias políticas que constituyen para Arendt los polos extremos de la modernidad - las revoluciones y el totalitarismo. A partir del análisis de estos dos elementos, me propongo dar a ver la manera en la que la pregunta por la diferencia entre diversas formas de organización política se constituye como un punto nodal a partir del cual es posible interpretar la empresa teórica arendtiana.
\end{abstract}

PALABRAS ClAVE: Política, revolución, totalitarismo, tradición, régimen.

\section{The question concerning the differences between regimes in Hannah Arendt's thought}

Is it possible to think, after the collapse of the tradition of political philosophy, about the difference between regimes? In this article I address this question in two parts. First, I will try to show how, in her reading of Montesquieu, Arendt discovers a way to think about the opposition between freedom and domination that goes beyond traditional parameters. Second, I will analyze the two political experiences that constitute, for Arendt, the extreme poles of modernity - revolutions and totalitarianism. Starting from these two elements, I will try to show how the question concerning the differences between regimes is at the core of Arendt's theoretical project.

KEY WORDS: Politics, revolution, totalitarianism, tradition, regime.

"Un mundo nuevo", afirma Tocqueville, "requiere una ciencia política nueva" (Tocqueville, 2002: 34). Desde Maquiavelo en adelante, el pensamiento político moderno se vio embarcado en la tarea de interpretar experiencias inéditas en la historia de la humanidad, fenómenos que no podían ser comprendidos con las herramientas conceptuales de la tradición filosófico-política. Esta dificultad - presente durante toda la modernidad- se tornó ineludible en el siglo XX. Atravesado por las guerras y las revoluciones, por la crisis del Estado como forma política y por la emergencia de los totalitarismos; en definitiva, por la entrada en

Sirczuk, Matías (2014), “La pregunta por la diferencia de regímenes en el pensamiento arendtiano", Lectora, 20: 161-174. ISSN: 1136-5781 
escena de fenómenos políticos que pulverizaron todas nuestras categorías de pensamiento y nuestros criterios de juicio, el siglo XX demandaba mucho más que cualquier otro la elaboración de un nuevo pensamiento capaz de dar cuenta de lo sucedido. De un modo mucho más radical que hasta entonces, los conceptos con los que la tradición había pensado la política, en lugar de echar luz sobre los acontecimientos del mundo, los tornaban más opacos.

En este escenario se insertan las reflexiones de Hannah Arendt. Arendt confronta estas experiencias partiendo del reconocimiento de que los fenómenos políticos que le eran contemporáneos no podían ser interpretados con las categorías ofrecidas por la tradición. Ni ciencia ni filosofía, el nuevo pensamiento que intenta desarrollar se caracteriza por una sensibilidad para pensar lo político conservando la posibilidad de juzgar lo existente anclando el juicio en la experiencia (Arendt, 1995b: 87). Contra la filosofía política y la teología política tradicional, ${ }^{1}$ pretende elaborar un pensamiento a partir del cual resulte posible comprender los fenómenos políticos centrales de la modernidad. ¿Cuáles son las experiencias que se encuentran en el corazón del pensamiento arendtiano?

Como es sabido, el fenómeno que desafía la comprensión, la experiencia política fundamental con la que su pensamiento ha tenido que confrontarse, es la emergencia de los totalitarismos. La aparición del antisemitismo moderno en la escena política del siglo XIX, la desintegración de las Naciones-Estados y su concepto de soberanía, el surgimiento del imperialismo como móvil de acción de las clases dominantes europeas; todos estos factores cristalizaron en una forma de dominación inédita en la historia de la humanidad. El totalitarismo, sostiene Arendt, ha pulverizado todas nuestras categorías de pensamiento y nuestros criterios de juicio (Arendt, 1990: 20; Id. 1995a: 31-32; Id. 2002: 30-42). La confrontación con esta experiencia, la asunción del carácter irreversible de la ruptura que significa, tanto para las formas en las que la tradición pensó la política como para los modos en los que las comunidades humanas se organizaron a lo largo de la historia (poniendo en crisis no sólo el pensamiento político sino también la distinción clásica entre tipos de régimen), se encuentra en el centro de sus reflexiones. Es este acontecimiento sin precedentes el que la obliga a repensar lo político en tanto que tal.

Ahora bien, si es cierto que la pérdida de guías, de estándares morales invariables, resultado de la ruptura de la tradición, habría regado el terreno para el surgimiento de los totalitarismos, la aparición de esta nueva forma de gobierno no es interpretada por Arendt en términos de necesidad o de causalidad, como si hubiera una línea de continuidad entre esta y la modernidad. El totalitarismo surge gracias a una cristalización específica de determinados elementos presentes

\footnotetext{
${ }^{1}$ Para una lectura de Arendt en esta clave pueden consultarse Abensour, 2006 y Buckler, 2011.
} 
en la Edad Moderna. ${ }^{2}$ El análisis de sus orígenes dibuja los contornos de una historia de la modernidad que - si la asociamos al relato que de ésta hace en $\mathrm{La}$ condición humana, en los términos del progresivo reemplazo de la acción por la labor, de la emergencia de la sociedad de masas y de la consecuente comprensión de la política en términos de administración de las necesidades de la población-, parece llevarnos a interpretarla como una época que señala la desaparición de la libertad y el ocultamiento de lo político; una época en la que se habría olvidado definitivamente la única causa que "ha determinado, desde el comienzo de nuestra historia, la propia existencia de la política, la causa de la libertad contra la tiranía" (Arendt, 2004: 11; la cursiva es propia).

No obstante, esta historia de la modernidad no es la única que relata Arendt, ni el totalitarismo es el único acontecimiento que le obsesiona comprender. Pretende contar también la "historia secreta de la Edad Moderna" (Arendt, 1995b: 77), una historia en la que lo político parece fulgurar con una luz hasta ahora desconocida, una historia que le permite pensar la fundación de la libertad de un modo enteramente novedoso. El totalitarismo no es -estrictamente hablando - ni la única ni la primera experiencia política moderna que carece de precedentes dentro de la tradición. Tal como escribe Fina Birulés,

el totalitarismo [...] no es la culminación de la época moderna sino una forma patológica especial de la política moderna. Para Arendt, no hay un vínculo interno entre la progresiva "pérdida del mundo", característica de la modernidad, y el terror, la esencia del totalitarismo. No debe sorprendernos, pues, que cuando escribe acerca de los acontecimientos históricos de su presente o del pasado lo haga fijando su atención en los dos polos extremos entre los que está comprendida la modernidad: el totalitarismo del siglo $\mathrm{XX}$ y el fenómeno de las revoluciones modernas. (Birulés, 2007: 109)

Si luego de la experiencia totalitaria su análisis apuntaba a comprender un acontecimiento que por su misma originalidad desafiaba todas nuestras categorías de pensamiento, y marcaba la ruptura definitiva con la tradición, en Sobre la revolución Arendt se habría enfrentado a un fenómeno de características similares: la revolución -como concepto y como acontecimiento político específico de la modernidad- tampoco podía ser comprendida con las categorías de aquella. Ambos análisis - que marcan los dos polos extremos de la modernidad- han de ser interpretados dentro de un proyecto mayor, que consiste en buscar, para decirlo en las palabras de Tocqueville que tanto gustaba

\footnotetext{
${ }^{2}$ Arendt utiliza Edad Moderna para hablar de la época que comienza en el siglo XVII y culmina a principios del siglo XX; y Mundo Moderno para referirse a la época posterior a las primeras explosiones atómicas. Con respecto a esta distinción véase Arendt, 2005a: 33-34 y Arendt, 1996a: 33.
} 
citar a Arendt, en un mundo nuevo, una nueva ciencia política capaz de dar cuenta de los acontecimientos políticos en su misma especificidad (Arendt, 2004: 69 y 243 ; Id. 1996b: 86).

La novedad que marcan ambos acontecimientos —el hecho de que ni el totalitarismo ni las revoluciones puedan ser interpretados bajo las categorías que la tradición utilizó para pensar y distinguir los regímenes políticos- obliga a Arendt a replantear la distinción clásica entre formas de gobierno. Si bien ni uno ni otro fenómeno pueden ser interpretados bajo la oposición entre tiranía y libertad -ni el totalitarismo puede comprenderse simplemente como una tiranía, ni la Revolución americana puede ser entendida como una república en el sentido tradicional- ambos expresan, en cierto modo, la forma moderna en la que dicha oposición aparece. Su carácter inédito sitúa a Arendt en el dominio del historiador o del pensador político tal como ella lo entiende; ${ }^{3}$ esto es, en el dominio de quien tiene que estudiar aquello que sólo ocurre una vez y tratar de captarlo en su contingencia radical (Arendt, 1995a: 41-42).

¿Es posible pensar, tras la ruina de la tradición de la filosofía política, la diferencia entre diversas formas de organización política? En este artículo propongo abordar este interrogante a través de una estrategia doble. La primera parte estará centrada en mostrar cómo, en su lectura de Montesquieu, Arendt descubre un modo de pensar la oposición entre régimen libre y dominación que trasciende los horizontes clásicos. En la segunda parte volveré sobre las dos experiencias políticas que constituyen para Arendt los polos extremos de la modernidad - las revoluciones y el totalitarismo-, con el objeto de dar a ver la manera en la que, iluminada por los "descubrimientos de Montesquieu", la pregunta por la diferencia entre diversas formas de organización política se constituye como un punto nodal a partir del cual interpretar la empresa teórica arendtiana.

\section{1. ¿Cómo pensar la diferencia entre regímenes más allá de la tradición? La lectura de Montesquieu}

En ¿Qué es la política? Arendt sostiene:

La pregunta por los principios de la acción ya no alienta nuestro pensamiento sobre la política desde que la cuestión de las formas de

\footnotetext{
${ }^{3}$ Arendt contrapone la comprensión clásica de la historia, cuya tarea primordial consistía en convertir los actos y las palabras, por naturaleza fugaces, en algo digno de recuerdo, con la moderna, que la entiende como proceso. La tarea del historiador, en tanto storyteller, consiste para ella en dar fama inmortal a las acciones de los seres humanos mediante la narración. Para una contraposición entre la historia clásica y moderna véase Arendt, 1996b: 49-52. En referencia al "método" arendtiano, su "old-fashioned storytelling", pueden consultarse: Vollrath 1977; Disch, 2011; Pirro, 2001; Benhabib, 1990 y Young-Bruehl, 1977.
} 
gobierno y por la mejor forma de convivencia humana ha caído en el silencio, esto es, desde las décadas de la Revolución americana a principios del siglo XVIII, durante las cuales se discutieron vivamente las posibles ventajas y desventajas de la monarquía, de la aristocracia y de la democracia, o de cualquier forma de gobierno que como república pudiera unificar elementos monárquicos, aristocráticos y democráticos. (Arendt, 1997: 136)

De modo similar, en Sobre la revolución, afirma que en la actualidad nadie parece estar interesado por las formas de gobierno, cuestión que estuvo en el centro de los debates de los padres fundadores (Arendt, 2004: 285, n. 43). Estas referencias, que aparecen aquí y allá a lo largo de la obra arendtiana, parecen sugerir que - al igual que los padres fundadores- Arendt pretende rescatar del silencio la pregunta por las diversas formas de convivencia, interrogar aquí $y$ ahora las "posibles ventajas y desventajas" de los distintos regímenes, abordar el problema de la mejor forma de gobierno y consecuentemente, la oposición entre el régimen libre y la tiranía (Arendt, 2004: 299-300). Pero la interrogación sobre esta cuestión no puede realizarse repitiendo el movimiento que llevó a la filosofía política clásica a formularla.

Desde Platón, afirma Arendt, todas las definiciones tradicionales acerca de la naturaleza de las distintas formas de gobierno han descansado en dos pilares: el poder y la ley. La diferencia entre ellas depende de la distribución del poder (poseído por uno solo en la monarquía, por los más distinguidos en la aristocracia o por el pueblo en la democracia). Su buena o mala naturaleza depende de un tipo particular de relación con la ley: el gobierno justo es aquel que gobierna de acuerdo a la ley. El injusto el que se rige contrariamente a lo que la ley dicta. Las tres formas pervertidas, ilegítimas, de gobierno son la tiranía, la oligarquía y la oclocracia o el gobierno de la plebe (Arendt, 2007: 713). El término tiranía, no obstante, fue utilizado también desde Platón para describir a todo gobierno que se organiza según la voluntad arbitraria de quien manda, sin importar que este gobierno estuviera constituido por uno, varios o todos. La distinción clásica, por tanto, descansa en la distribución del poder y en la discriminación entre gobierno legal y arbitrario. La diferencia entre gobiernos legítimos y gobiernos ilegítimos se basa en la relación que en cada caso se establece con la ley.

Ahora bien, esta formulación tradicional de la distinción entre formas de gobierno, originada en Platón, no fue el resultado de un interés por interrogar los diversos modos en los que los seres humanos viven en común (no estuvo orientada por una preocupación particular por la esfera de los asuntos humanos). Por el contrario, su razón de ser remite a la búsqueda de un régimen que ofrezca garantías para la seguridad del filósofo. Para decirlo de otro modo: la distinción clásica de formas de gobierno - y su consecuente jerarquía- no fue pensada para establecer la forma más libre de convivencia sino para asegurar la 
supervivencia del filósofo. Inserta en la tradición de pensamiento, se conservó a lo largo de la historia: ni la República ni el Imperio romanos, ni la monarquía medieval de matriz teológico-política, ni la emergencia de las Naciones-Estados con su moderno concepto de soberanía, parecen haber compelido a la filosofía política a revisar la adecuación de la formalización platónica de los distintos modos de convivencia humana.

Estas consideraciones, afirma Arendt, son necesarias para comprender a Montesquieu, el último pensador que trató de confrontar los problemas políticos elementales volviendo su mirada al antiguo problema de la distinción entre las formas de gobierno (Arendt, 2005a: 228). Arendt señala que Montesquieu ocupa un lugar muy particular en relación a la tradición de la filosofía política. Su concepción del poder y de la ley está elaborada a contrapelo de todas las enseñanzas heredadas: el poder es identificado con la libertad (Arendt, 2004: 201202); la ley es entendida como aquello que establece relaciones (Arendt, 2004: 203, n. 18).

Uno de sus grandes descubrimientos, el carácter divisible del poder, lo llevó a elaborar la distinción entre las tres ramas de gobierno. Esta distinción, "que procede de Montesquieu y que encontró expresión inequívoca en la Constitución de los Estados Unidos" (Arendt, 2005b: 397-398), fue utilizada por Kant para reducir la clasificación clásica entre formas de gobierno a una oposición binaria: o bien existe un gobierno constitucional que se rige de acuerdo a la ley, o bien hay despotismo y dominación (Arendt, 2007: 714). Pero esta reformulación de Kant, afirma Arendt, resulta todavía insatisfactoria: para él, la ley tiene origen en la razón (es pensada en el sentido de lumen naturale y, por tanto, es entendida como mandato) y el poder se enraiza en la voluntad (Arendt, 2005b: 398). Por el contrario, Arendt sostiene que bajo el descubrimiento de las tres ramas de gobierno descansa un pensamiento político en el que el poder está disociado completamente de las connotaciones tradicionales que lo vinculan a la violencia. Una concepción del poder que hunde sus raíces en la comprensión de que la acción - no la dominación - es el corazón mismo de toda vida política.

Esta sensibilidad para lo político llevó a Montesquieu a elaborar la distinción entre las formas de gobierno no solamente a partir de "aquello que las hace ser" —en términos tradicionales, su naturaleza-, sino también a partir de "aquello que las hace actuar" —en sus palabras, los principios de acción- (Arendt, 2008: 99). Sumado al reconocimiento del carácter divisible del poder, los principios de acción aparecen como el otro gran descubrimiento de Montesquieu. Subvirtiendo la preocupación clásica que identifica el movimiento con la perversión de una forma particular de gobierno, Montesquieu desarrolla una indagación acerca de los modos en los que la misma acción contribuye a la conservación de un régimen político particular. Este desplazamiento lo lleva a sustituir la distinción clásica entre formas de gobierno - asentada en la búsqueda del modo más adecuado de garantizar formas de vida no políticas - por una 
clasificación cuyo centro está ordenado por la descripción de los diversos principios de acción. Entendidas desde un punto de vista específicamente político - esto es, interpretadas bajo la comprensión de que la acción es el corazón de la política- las estructuras de gobierno se dividen en tres: república, monarquía y tiranía. La virtud se instituye como principio de acción de la república. El honor es el resorte de la monarquía. El temor el de la tiranía. Arendt sugiere también que estas tres formas de gobierno parecen ocultar una diferencia más profunda entre aquellos regímenes que son capaces de reproducirse y generar poder - la república y la monarquía - gracias a que sus principios de acción se asientan en la condición humana de la pluralidad, de la tiranía. Esta última destruye el espacio político condenando a los seres humanos al aislamiento - "genera impotencia de manera tan natural como otros cuerpos políticos generan poder" - por lo que no puede ser interpretada como una forma de gobierno entre otras sino que ocupa un lugar particular en el interior de la distinción (Arendt, 2005: 228-229 y Arendt, 1981: 602-603).

Al igual que los revolucionarios americanos, Arendt descubre en Montesquieu a un compañero de viaje indispensable para repensar lo político. En la senda abierta por él, interroga los modos en los que los seres humanos se agrupan entre sí a partir de los "principios energéticos" (Arendt, 2002: 433). No obstante, a pesar de esta afinidad, es preciso señalar dos puntos fundamentales para pensar arendtianamente la cuestión.

El primer punto consiste en indicar que, más allá del carácter innovador del pensamiento de Montesquieu a este respecto, Arendt considera que la reducción de los principios de acción a tres "parece inadecuada frente a la diversidad de los modos en los que los seres humanos habitan el mundo" (Arendt, 2002: 435). Los principios de acción, sostiene Arendt, aparecen fenoménicamente en el mundo como resultado de la fundación (Arendt, 2004: 291-295); por tanto —dada la capacidad del ser humano para la novedad- limitarlos solamente a tres resulta arbitrario. Ahora bien, si este vínculo con la fundación y la novedad parece habilitar la posibilidad de pensar que los principios (y por tanto las formas de gobierno) son ilimitados, Arendt acota esta vía de interpretación añadiendo que las diversas formas políticas se asientan en alguna de las pocas experiencias fundamentales que pueden tener los seres humanos allí donde viven juntos. Para decirlo de otro modo: los principios de acción - y consecuentemente, las formas de gobierno- no pueden ser reducidos a tres debido a la capacidad del ser humano para hacer aparecer lo nuevo; pero a la vez, esta multiplicación no puede ser infinita ya que toda forma de organización política se asienta en alguna experiencia fundamental del ser humano, experiencias que para Arendt son acotadas. $^{4}$

\footnotetext{
${ }^{4}$ En el contexto del análisis del totalitarismo, Arendt señala que - para poder analizarlo como una nueva forma de gobierno- es preciso descubrir cuál "de las pocas experiencias básicas que
} 
El segundo punto consiste en comprender que, a diferencia de Montesquieu, quien escribía en un contexto en el cual aún no se habían soltado todas las amarras que nos ligaban al pasado, Arendt se enfrenta a modos de organización de la vida en común que difícilmente pueden ser identificados con las formas de gobierno tradicionales. Ni la monarquía, ni la república tal como la describe Montesquieu, ni la tiranía, parecen coincidir con las experiencias políticas centrales de la modernidad. ${ }^{5}$ Si bien Arendt afirma que "[d]ifícilmente hay un acontecimiento de alguna relevancia de nuestra historia reciente que no pueda encajar en los esquemas conceptuales de Montesquieu" (Arendt, 2005b: 396), no obstante sugiere también que, cuanto menos, el totalitarismo expresa un tipo de organización política que no se ajusta a sus parámetros.

En este sentido, pareciera ser que la emergencia de una experiencia inédita de libertad en el transcurso de la Revolución americana, combinada con el surgimiento del totalitarismo como una forma de gobierno enteramente novedosa, habilitan una interpretación del análisis que Arendt hace de estos fenómenos que obliga a reinterrogar la distinción clásica entre formas de gobierno: si "los pilares de las verdades más conocidas" (Arendt, 1990: 20) yacen destruidos, parece por tanto imprescindible pensar de nuevo la oposición clásica entre libertad y tiranía, entre gobiernos legítimos y gobiernos arbitrarios.

\section{Los dos polos de la modernidad, o la diferencia moderna entre libertad y tiranía}

Al iniciar nuestro recorrido señalamos que para Arendt la modernidad está constituida por dos polos antagónicos: las revoluciones y el totalitarismo. Ambos fenómenos, observábamos, revelan acontecimientos que no son posibles de comprender con las herramientas conceptuales de la tradición. También indicábamos que si bien el diagnóstico de Arendt con respecto a la modernidad podía ser interpretado como el de una época en la que lo político tiende a desaparecer, ${ }^{6}$ para ella la modernidad es también la era de las revoluciones.

los hombres pueden tener allí donde viven juntos y se hallan ocupados por los asuntos públicos" se revela como su fundamento (Arendt, 1981: 596). La cursiva es propia.

${ }^{5}$ Cabe destacar asimismo que la distinción entre las formas de gobierno tripartita desarrollada al comienzo de El espíritu de las leyes (asentada a la vez en la naturaleza del gobierno y el principio de acción) se "ensucia" en el contexto del análisis de la Constitución inglesa, en donde Montesquieu añade que los regímenes políticos también pueden diferenciarse según el fin que promueven. La Constitución inglesa, a la vez que no parece ser encasillada fácilmente en ninguna de las tres formas de gobierno "puras", aparece como el primer régimen que tiene como fin la libertad política.

${ }^{6}$ En este sentido deben interpretarse, entiendo, los capítulos finales tanto de La condición humana como de Sobre la revolución. En ambos textos, luego de llegar al punto más alto de su argumento en lo que refiere al elogio de la acción y de la política, Arendt pasa a describir las dificultades que tuvieron tanto la Revolución americana para dotarse de una institución que 
En las últimas páginas de Los orígenes del totalitarismo, Arendt afirma que "la crisis de nuestro tiempo y su experiencia central" han generado "una forma enteramente nueva de gobierno [el totalitarismo] que, como potencialidad y como peligro siempre presente, es muy probable que permanezca con nosotros a partir de ahora" (Arendt, 1981: 615). Especularmente, en La condición humana sostiene que

[1]o que fácilmente pasa por alto el historiador moderno que se enfrenta al auge de los sistemas totalitarios, en especial cuando se trata de los progresos en la Unión Soviética, es que de la misma manera que las masas modernas y sus líderes lograron, al menos temporalmente, producir en el totalitarismo una auténtica, si bien destructiva, forma de gobierno, las revoluciones del pueblo han adelantado durante más de cien años, aunque nunca con éxito, otra nueva forma de gobierno: el sistema de los consejos populares. (Arendt, 2005a: 239-240)

En este sentido, su interpretación de las revoluciones, aunque de un modo mucho más asistemático que su análisis sobre el totalitarismo, ofrece también pistas que indican la emergencia de "los rudimentos de una forma de Gobierno enteramente nueva” (Arendt, 1998: 232). ${ }^{7}$ No obstante, Arendt entiende que - $a$ diferencia del totalitarismo- las revoluciones, cuyo "tesoro perdido" parece referir a la emergencia de una forma de organización política capaz de conservar el espíritu revolucionario, no han logrado cristalizar en instituciones políticas duraderas, no han podido constituir un régimen político en donde la libertad pública o la felicidad pública pudiera manifestarse reiteradamente. Orientados por la indagación en torno a esta diferencia, pasemos entonces a describir esquemáticamente la contraposición entre estas nuevas "formas de gobierno" que parece emerger del análisis arendtiano.

El totalitarismo carece de precedentes porque desafía toda comparación. Pero ¿es aún posible interpretarlo como una forma de gobierno? ¿Ha dado lugar a una configuración particular entre "aquello que lo hace ser", su naturaleza, y "aquello que lo hace actuar", su principio? ¿Se asienta en alguna de las pocas experiencias fundamentales que tienen los seres humanos allí donde viven juntos?

conservase el espíritu de la libertad, como la acción política para actualizarse en las condiciones sociales, históricas y políticas de la modernidad. Recordemos que el último apartado de $\mathrm{La}$ condición humana se denomina "La victoria del animal laborans" y que Sobre la revolución concluye haciendo referencia a René Char y a la metáfora del "tesoro perdido" de las revoluciones.

${ }^{7}$ Se pueden encontrar más referencias acerca de esta otra nueva forma de gobierno en Arendt, 2004: 29, 42, 74, 121, 160, 201, 285, 298-299, 337, 353, 361. 
En primer lugar, Arendt señala que el totalitarismo no puede ser interpretado como un modo fenoménico de aparición de la tiranía debido a que, desde Platón, la tiranía descansa en la distinción entre régimen legal y arbitrariedad. Por el contrario, entiende que esta nueva forma de dominación "[h]a explotado la alternativa misma sobre la que se han basado en filosofía política todas las definiciones de la esencia de los Gobiernos, es decir, la alternativa entre el Gobierno legal y el ilegal, entre el poder arbitrario y el legítimo" (Arendt, 1981: 596).

A la vez que desafía todas las leyes positivas, el totalitarismo no opera sin la guía del derecho; por el contrario pretende actualizarlo en la tierra sin necesidad de mediación alguna (Arendt, 1981: 596-597). En este sentido, sostiene que si en las formas de gobierno tradicionales la ley positiva traducía a normas concretas principios que se consideraban estables y permanentes, por el contrario, bajo el totalitarismo - en la medida en que la distancia entre legalidad y legitimidad se difumina - el terror se constituye como el medio más adecuado para intentar adecuar la ley, concebida como ley de movimiento, a la realidad: "[s]i la legalidad es la esencia del Gobierno no tiránico y la ilegalidad es la esencia de la tiranía, entonces el terror es la esencia de la dominación totalitaria" (Arendt, 1981: 600). Este elemento sería, en palabras de Montesquieu, "aquello que lo hace ser". ¿Qué es lo que lo hace actuar?

La ideología - su lógica inherente- es para Arendt el segundo componente característico de la forma de gobierno totalitaria. A pesar de no poder ser interpretado exactamente como un principio de acción ya que no inspira a los individuos a actuar sino que los prepara - mediante el despliegue de la lógica de una idea llevada hasta sus últimas consecuencias- para cumplir la función que el desarrollo de las fuerzas de la historia o de la naturaleza demanden, la ideología es aquello que le permite al régimen durar en el tiempo sin mudar su naturaleza. Ofrece una explicación de la realidad que se torna independiente de la experiencia y prepara indistintamente a los individuos que viven bajo esos regímenes para ocupar tanto el papel de víctimas como de victimarios. En lugar de inspirar las acciones de los seres humanos, favorece un "comportamiento" individual tendiente a reproducir las condiciones de dominación en las que se asienta el totalitarismo (Arendt, 1981: 609): ${ }^{8}$

La coacción del terror total, por un lado, que, con un anillo de hierro, presiona a las masas de hombres aislados y las mantiene en un mundo que se ha convertido en un desierto para ellos, y la fuerza autocoactiva de la deducción lógica, por otro, que prepara a cada individuo en su

\footnotetext{
${ }^{8}$ Señalemos aquí que Arendt no vuelve a referir a este concepto de ideología como clave para pensar los comportamientos individuales bajo los regímenes totalitarios ni siquiera en su análisis de Eichmann, en donde el criterio que permite comprenderlos no es la ideología sino la ausencia de pensamiento y de capacidad de juicio. Véase Arendt, 1999.
} 
aislamiento solitario contra todos los demás, se corresponden mutuamente y se necesitan mutuamente para mantener constantemente en marcha el movimiento gobernado por el terror. (Arendt, 1981: 610)

Finalmente, Arendt afirma que el terror - como sustituto de la esencia del régimen - y la ideología - como sustituto del principio de acción- se asientan en la experiencia del aislamiento, experiencia que hasta ahora no había sido el fundamento de ninguno de los regímenes políticos conocidos en la historia (Arendt, 1981: 610-616). Esta configuración particular cristaliza en un tipo de dominación inédita que niega - in toto - la pluralidad inherente a la condición humana. Como observamos, Arendt afirma que el totalitarismo carece de precedentes porque desafía toda comparación. La crisis de nuestro tiempo y su experiencia central,

han producido una forma enteramente nueva de gobierno que, como potencialidad y como peligro siempre presente, es muy probable que permanezca con nosotros a partir de ahora, de la misma manera que otras formas de gobierno -monarquía, república, tiranía, dictadura, despotismo- que surgieron en diferentes momentos históricos y se basan en experiencias fundamentales diferentes, han permanecido con la Humanidad al margen de sus derrotas temporales. (Arendt, 1981: 615; la cursiva es propia)

¿Es posible afirmar que "al margen de sus derrotas temporales", la nueva forma de gobierno que ha aparecido - para desaparecer rápidamente- en cada revolución también permanezca con nosotros? ¿No podemos imaginar que la ruptura del hilo que nos unía con la tradición haya traído no sólo un nuevo tipo de dominación sino también un modo inédito de vivir en común libremente?

Varios índices presentes a lo largo de la obra de Arendt nos llevan a considerar que una respuesta afirmativa a estos interrogantes es, a la vez, verdadera y falsa. Es cierta en la medida en que, para Arendt, en todas las revoluciones ha surgido una nueva forma de gobierno que parece coincidir con la gramática de la acción y emerger solamente a partir de ella:

Desde las revoluciones del siglo XVIII, todo gran levantamiento ha desarrollado los rudimentos de una forma de Gobierno enteramente nueva, que surgió independiente de todas las anteriores teorías revolucionarias, directamente del curso de la misma revolución, es decir, de las experiencias de la acción y de la resultante voluntad de los ejecutantes para participar en el desarrollo posterior de los asuntos públicos. Esta nueva forma de gobierno es el sistema de consejos que, como sabemos, ha perecido cada vez y en cada lugar, destruido, bien directamente por las burocracias de las Naciones-Estados, bien por las 
maquinarias de partido [...]. Me parece, sin embargo, la única alternativa que ha aparecido en la Historia y que ha reaparecido una $y$ otra vez. La organización espontánea de los sistemas de consejos se verificó en todas las Revoluciones, en la Revolución francesa, con Jefferson en la Revolución americana, en la Comuna de París, en las revoluciones rusas, tras las revoluciones en Alemania y Austria después del final de la Primera Guerra Mundial y, finalmente, en la Revolución húngara. Aún más: jamás llegaron a existir como consecuencia de una tradición o teoría conscientemente revolucionarias, sino que surgieron de forma enteramente espontánea en cada ocasión, como si jamás hubiera existido nada semejante. Por eso, el sistema de consejos parece corresponder a la verdadera experiencia de la acción política y surgir de ésta. (Arendt, 1998: 232; la cursiva es propia)

Pero a la vez, una respuesta afirmativa a esas preguntas es falsa - o cuanto menos problemática-, en la medida en que para Arendt los consejos no llegaron nunca, ni siquiera en Estados Unidos, a cristalizar en una nueva forma de organización política. Si el relato que Arendt realiza de la Revolución americana, en tanto fenomenología de la emergencia de la promesa como el principio de acción del cual brota la legitimidad de la fundación, pareciera favorecer una respuesta positiva a las preguntas recién planteadas, lo cierto es que el análisis arendtiano no concluye ahí: el progresivo reemplazo de la felicidad pública por la búsqueda de bienestar privado, la derrota de los consejos por las maquinarias de los partidos políticos, el ascenso de lo social y la consolidación de la lógica propia de las burocracias estatales; todos ellos han contribuido a obstaculizar la cristalización de esta nueva experiencia política en un tipo de régimen inédito. La revolución, afirma Arendt, no logró dotarse de una institución perdurable capaz de preservar el espíritu que había emergido al calor de los acontecimientos (Arendt, 2004: 319-320). Su consecuencia ha sido la desaparición de un espacio en el cual los seres humanos pudieran experimentar la libertad política de modo relativamente frecuente:

[t]odo esto, y probablemente mucho más, lo perdimos cuando el espíritu de la Revolución - un espíritu nuevo y, a la vez, el espíritu de comenzar algo nuevo- no logró encontrar su institución adecuada. No hay nada que pueda compensarnos de esta pérdida ni de evitar su carácter irreparable, salvo la memoria y el recuerdo. (Arendt, 2004: 388; traducción modificada $)^{9}$

\footnotetext{
${ }^{9} \mathrm{Si}$ bien Arendt sostiene que vislumbra en este tipo de organización política "la posibilidad de formar un nuevo concepto del Estado" y añade que "[u]n Consejo estatal de este tipo, al que debería ser completamente extraño el principio de la soberanía, resultaría admirablemente 
Concluyamos: como observamos al comienzo, la confrontación con la experiencia del totalitarismo - la asunción del carácter irreversible de la ruptura que significa, tanto para las formas en las que la tradición pensó la política como para los modos en los que las comunidades humanas se organizaron a lo largo de la historia, se constituye para Arendt en el punto de partida, la experiencia fundamental, que la lleva a repensar lo político de modo radical. A partir de esta experiencia elabora una interpretación del totalitarismo que articula, de un modo particular, los elementos que permiten dibujar los contornos de una forma inédita de gobierno. Arendt nunca escribió un texto similar al capítulo con el que concluye Los orígenes del totalitarismo, que diera cuenta sistemáticamente y describiera con claridad cuál sería la naturaleza y el principio de acción -como así también la experiencia fundamental que estaría en su base- de esa otra forma de convivencia que destella y desaparece en cada revolución. No lo hizo, entiendo, porque - como se ha señalado - consideraba que esta articulación particular evidenciaba sólo "los rudimentos" de una nueva forma de gobierno, que no ha logrado configurarse definitivamente como régimen político en la modernidad. No obstante, diversos elementos presentes a lo largo de su obra nos ofrecen indicadores para pensar que esta otra forma de régimen se instituye para ella como el contrapunto de la experiencia del terror totalitario. Nos toca a nosotros seguir indagando en los intersticios de su obra para recuperar criterios que nos permitan distinguir entre formas de organización política que acogen la libertad de aquellas que las niegan.

\section{REFERENCIAS BIBLIOGRÁFICAS}

Abensour, Miguel (2006), Hannah Arendt contre la philosophie politique?, París, Sens \& Tonka éditeurs.

Arendt, Hannah (1981), Los orígenes del totalitarismo, Madrid, Alianza Editorial. -(1990), "Sobre la humanidad en tiempos de oscuridad. Reflexiones sobre Lessing", Hombres en tiempos de oscuridad, Barcelona, Gedisa: 13-41.

-(1995a), "Comprensión y política", De la historia a la acción, Barcelona, Paidós: 29-46.

-(1995b), "La brecha entre el pasado y el futuro", De la historia a la acción, Barcelona, Paidós: 75-88.

-(1996a) "La tradición y la época moderna", Entre el pasado y el futuro. Ocho ejercicios sobre la reflexión política, Barcelona, Península: 23-47.

conveniente para federaciones de los más variados géneros, especialmente porque en él el poder sería constituido horizontal y no verticalmente"; concluye afirmando que "si usted me pregunta ahora qué posibilidades tiene de ser realizado, entonces tengo que decirle: Muy escasas, si es que existe alguna. Y si acaso, quizá, al fin y al cabo, tras la próxima revolución" (Arendt, 1998: 234). 
-(1996b), "El concepto de historia: antiguo y moderno", Entre el pasado y el futuro. Ocho ejercicios sobre la reflexión política, Barcelona, Península: 49-100. -(1997), ¿Qué es la política?, Barcelona, Paidós.

-(1998), "Pensamientos sobre política y revolución", Crisis de la república, Madrid, Taurus-Santillana: 201-234.

-(1999), Eichmann en Jerusalén. Un estudio sobre la banalidad del mal, Barcelona, Lumen.

-(2002), La vida del espíritu, Barcelona, Paidós.

-(2004), Sobre la revolución, Madrid, Alianza Editorial.

-(2005a), La condición humana, Barcelona, Paidós.

-(2005b), "De la naturaleza del totalitarismo. Ensayo de comprensión", Ensayos de comprensión. 1930-1954, Madrid, Caparrós: 395-434.

-(2007), "The Great Tradition. I: Law and Power", Social Research, 74, 3: 713726.

-(2008), "La revisión de la tradición por parte de Montesquieu", La promesa de la política, Barcelona, Paidós: 99-105.

Benhabib, Seyla (1990), "Hannah Arendt and the Redemptive Power of Narrative", Social Research, 57, 1: 167-196.

Birulés, Fina (2007), Una herencia sin testamento: Hannah Arendt, Barcelona, Herder.

Buckler, Steve (2011), Hannah Arendt and Political Theory. Challenging the Tradition, Edimburgo, Edinburgh University Press.

Disch, Lisa (2011), "Más verdadero que los hechos. Storytelling como comprensión crítica en los escritos de Hannah Arendt", Taula. Quaderns de Pensament, 43: 77-104.

Forti, Simona (2001), Vida del espíritu y tiempo de la polis. Hannah Arendt entre filosofía y política, Madrid, Cátedra.

Pirro, Robert C. (2001), Hannah Arendt and the Politics of Tragedy, Illinois, Northern Illinois University Press.

Tocqueville, Alexis de (2002), La democracia en América, Madrid, Alianza Editorial.

Vollrath, Ernst (1977), "Hannah Arendt and the Method of Political Thinking", Social Research, 44.1: 160-182.

Young-Bruehl, Elisabeth (1977), "Hannah Arendt's Storytelling", Social Research, 44. 1: 183-190. 